\title{
Resource Partitioning of Sympatric African Wolves (Canis lupaster) and Side-Striped Jackals (Canis adustus) in an Arid Environment from West Africa
}

\author{
Maria João Paúl ${ }^{1}\left(\mathbb{D}\right.$, Jorge F. Layna ${ }^{2}$, Pedro Monterroso ${ }^{1}\left(\mathbb{D}\right.$ and Francisco Álvares ${ }^{1, *}$ \\ 1 CIBIO/InBIO, Centro de Investigacão em Biodiversidade e Recursos Genéticos, Universidade do Porto, \\ Campus de Vairão, 4485-661 Vairão, Portugal; maariapaul@gmail.com (M.J.P.); \\ pmonterroso@cibio.up.pt (P.M.) \\ 2 Consultores en Iniciativas Ambientales, S.L., Organismo Autónomo Parques Nacionales, C/Arquitectura 7, \\ 28005 Madrid, Spain; j.f.layna@gmail.com \\ * Correspondence: falvares@cibio.up.pt; Tel.:+351-9660-34142
}

Received: 14 September 2020; Accepted: 11 December 2020; Published: 15 December 2020

check for updates

\begin{abstract}
Knowledge on interference competition between species, particularly for scarce crucial resources, such as water, is a topic of increasing relevance for wildlife management given climate change scenarios. This study focuses on two sympatric canids, the African wolf and the side-striped jackal, to evaluate their group size and spatiotemporal activity patterns in the use of a limited resource by monitoring artificial waterholes in a semi-arid environment located in Senegal (West Africa). Remote cameras were deployed at five artificial waterholes to evaluate the number of individuals, age and activity patterns of resource use. African wolves ( $\mathrm{n}=71 ; 31 \%$ of all carnivore detections) and side-striped jackals $(\mathrm{n}=104 ; 45 \%)$ were the most detected carnivore species. While both canids tended to occur alone at waterholes, they showed an evident monthly variation in group size. Both species showed a high activity overlap, with a bimodal activity pattern in waterhole use. However, we found evidence of unidirectional spatiotemporal avoidance, suggesting African wolves might be dominant over side-striped jackals. Our findings provide useful insights to investigate niche partitioning on the use of limited resources and have conservation implications for regions with a prolonged dry season.
\end{abstract}

Keywords: Canis lupaster; Canis adustus; circadian activity; group size; waterhole use; breeding phenology

\section{Introduction}

Describing and understanding animal activity can yield crucial insights into key factors affecting animal life, which can be relevant to understand wildlife ecology and to develop conservation plans [1,2]. Animal activity patterns are regulated internally by an endogenous clock but can be influenced by masking factors which may distort the main rhythm [2]. Masking factors can be both abiotic factors, such as light intensity and temperature, and biotic factors, such as human disturbance or intra and interspecific interactions [2]. Hence, activity patterns can be partly adjusted according to environmental conditions [1]. Interspecific interactions play a particularly important role in shaping behavioural patterns, which may be adjusted to maximize energetic gains and other biological needs, while reducing individual costs such as agonistic encounters with potential competitors and predators [1]. Competition among individuals can be expressed in two forms: (i) exploitation competition, whereby one species reduces the availability of a shared resource to the other; and (ii) interference competition, by which one species limits the other's access to shared resource through behavioural interactions [3]. Although exploitation competition is more commonly studied, 
interference competition can be just as important and even more costly, either through physical injury, interspecific killing or through reduction in food intake rate [4], with potentially profound consequences to the structure of animal communities $[5,6]$.

The scarcity of vital resources induces wildlife competition, which is likely to lead to interference behaviour [5]. When a vital common resource has limited geographic distribution, temporal segregation in its use can be a crucial mechanism allowing sympatric species to coexist [7]. The Sahel ecoclimatic zone in Africa comprises a semi-arid environment, characterised by little productivity and low species densities [8]. Species occurring in this region are useful models for investigating the effects of extreme environments on biodiversity as their range and foraging behaviour are greatly determined by climatic constraints [9] and ecological gradients [10], especially under the climate change scenarios which are predicted to be particularly impactful in the Sahel ecoclimatic zone [8]. During the dry season, water availability becomes a particularly limiting factor, and both wildlife and livestock converge at waterholes to maintain their hydric homeostasis [11]. Reduced water availability has the potential to lead to interference competition as a means of securing access to this vital resource $[5,12]$. Thus, the Sahel ecosystem provides a perfect setting to investigate wildlife interactions when forced to spatially converge at waterhole sites [5]. However, few studies have addressed interspecific interactions focusing on this African bioregion.

Canids are a well suited group to study interference competition as ecologically similar species tend to occur in sympatry, are often widely distributed, inhabit a wide variety of habitats and have a high flexibility in their ecological requirements [13,14]. The African wolf (Canis lupaster) and the side-striped jackal (Canis adustus) are two poorly studied species with a wide distribution but a limited range overlap, particularly in West Africa [13,15]. These two canids have a similar body size [16,17], exhibit a generalist diet consisting of small-sized vertebrates [18-20] and have predominantly crepuscular and nocturnal activity patterns $[19,21]$. The African wolf has become a newly recognized taxon, as recent evidence has confirmed its evolutionary differentiation from the Eurasian golden jackal $[15,16,22,23]$. Thus, many aspects of African wolf biology across its entire range are almost unknown and are considered research priorities [15]. The side-striped jackal is also recognized as one of the less studied extant canids worldwide, lacking basic knowledge on its biology and ecology across most of its range $[13,19]$. In fact, the few available studies on African wolves and side-striped jackals focusing on traits such as activity patterns, socio-biology and reproduction, came from East Africa, which comprises a small fraction of their distribution range $[15,19,24]$. Furthermore, there is also limited knowledge on the ecological interactions between these two species due to the limited extent of areas where they occur in sympatry as well as to the remoteness and political instability of the countries where these species co-occur, particularly along the Sahel ecoclimatic zone $[13,24]$. Since the area where these two canids occur in sympatry coincides mostly with semi-arid environments [13,19], interference competition for limited resources, such as surface water, is expected to affect their behavioural ecology. Consequently, acquiring ecological and behavioural knowledge regarding the interspecific interactions in water use, particularly in the semi-arid environments of West Africa, is mandatory to properly manage both wildlife and natural resources, especially in the light of ongoing climate change and human encroachment in wilderness areas $[5,11,25]$.

In this study, we comparatively assess the group size and spatiotemporal activity patterns of the African wolf and the side-striped jackal at artificial waterholes in a semi-arid environment located in Senegal (West Africa). We hypothesize that these species should segregate around waterholes as a way of reducing competitive stress by minimizing the likelihood of potentially agonistic encounters. 


\section{Materials and Methods}

\subsection{Study Area}

Our study was conducted in the Ferlo Nord Wildlife Reserve (central Senegal, West Africa; Figure 1), a protected area with 487,000 ha and dominated by Sahel's natural vegetation consisting of dry grassland with scattered trees and bushes, which in some areas can form dense patches of arboreal vegetation [26]. The area is covered predominantly by sandy soils with small amounts of clay [27]. There are few permanent settlements inside the reserve and the neighbouring areas (average human population density of 5 inhabitants $/ \mathrm{km}^{2}$ ) and livestock is the main economic source [26]. Camera trapping was carried out in 5 artificial waterholes (average distance between surveyed waterholes $=9.8 \mathrm{~km}$; $\max .=17.9 \mathrm{~km}$; $\min .=0.8 \mathrm{~km}$ ), which were located inside the 84,000 ha core central area under strict protection of the Ferlo Nord Wildlife Reserve, where human population is scarce and habitat is best preserved.

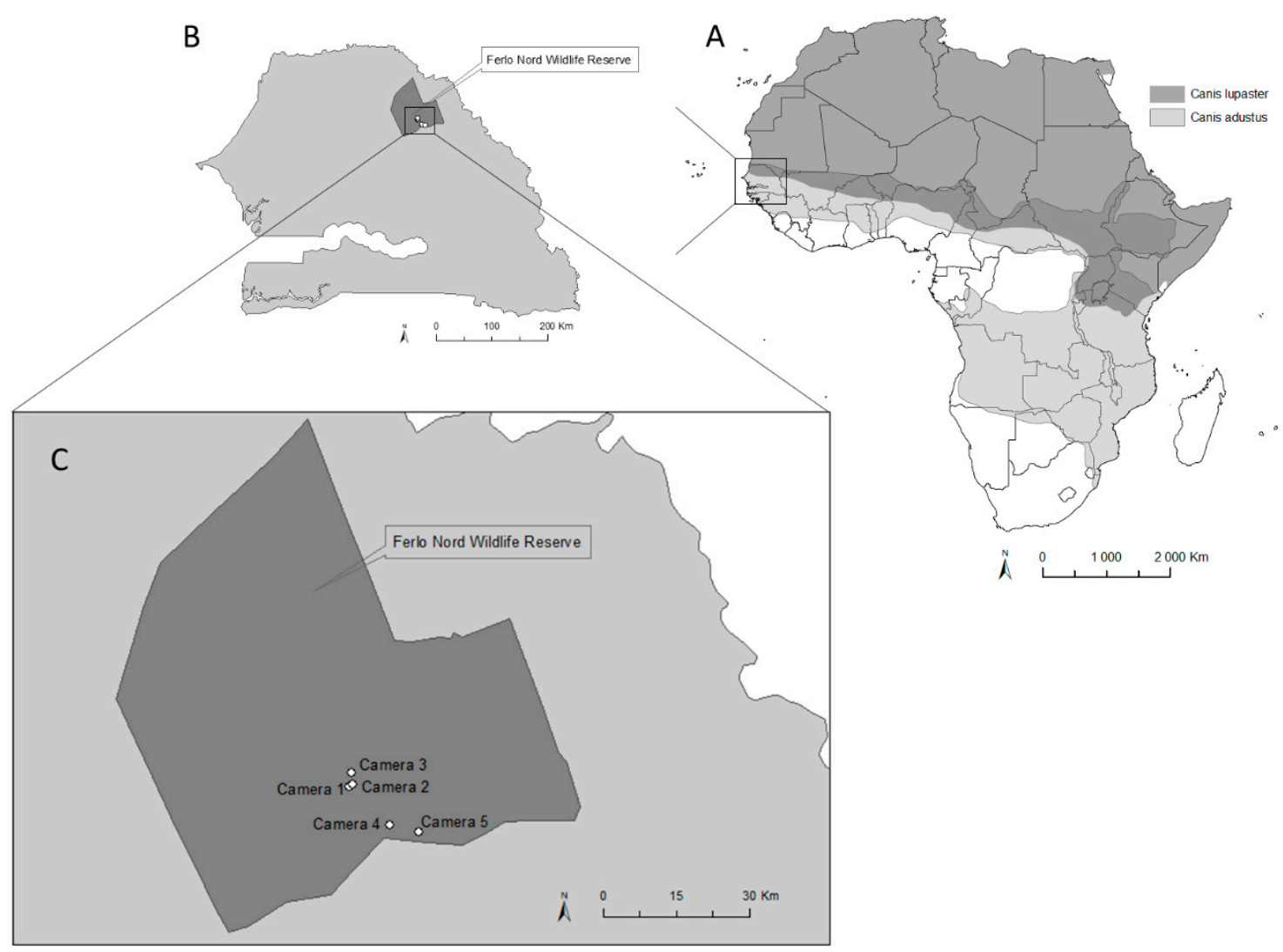

Figure 1. Distribution of the African wolf (Canis lupaster) and the side-striped jackal (Canis adustus) in Africa, and their range overlap (darkest grey) (source: https://www.iucnredlist.org/) (A). Location of the study area in Ferlo Nord Wildlife Reserve (Senegal, West Africa) (B) and the positions of the 5 artificial waterholes monitored by camera-trapping (C).

Sahel's climate is characterized by high temperatures all year round with a short wet season (July to October) and a longer dry season that can last up to 8-9 months (November to June). In the Ferlo region, annual rainfall ranges from 120 to $880 \mathrm{~mm}$, with an average ranging from 400 to $500 \mathrm{~mm}$ [28].

\subsection{Data Collection and Analysis}

We collected data through camera-trapping during field expeditions by placing a total of 5 passive infrared-triggered cameras (ScoutGuard SG550) near 5 artificial waterholes (one camera per waterhole), 
which were constructed for wildlife conservation purposes. We placed all cameras in trees at approximately $150 \mathrm{~cm}$ off the ground and programmed the cameras to record high resolution videos $(720 \times 480)$ with $1 \mathrm{~s}$ trigger time. We set the cameras during the dry season within different time intervals ranging from May 2011-June 2011 and from October 2011-March 2012, comprising a total trapping effort of 329 night-traps (Figure S1, mean trapping effort per camera $=66 \pm 42$ night-traps).

For each detection record, we recorded the date, time, species, age and number of individuals. We based species identification on morphological characters as described in field guides and other literature with wildlife pictures or drawings (e.g., $[17,19])$. We classified age as "adult" or "pup" ( $<6$ months old) based on body size and morphological traits. We considered detection records as distinct when recorded at $>5$ min intervals between videos, and as independent when recorded at $>30 \mathrm{~min}$ intervals $(\Delta t \geq 30 \mathrm{~min}$ ), unless individuals were unambiguously identified [29,30]. We only used independent events for all subsequent analyses.

Data analyses comprised the calculation of detection rates (number of independent records/total trapping effort) per 100 night-traps. For both canids, we based the examination of group size on the number of detected adults and pups. We also assessed temporal variation in the number of detected individuals by every month in which cameras were active.

We estimated the activity level, defined as the proportion of time an animal spends active in a diel cycle, by fitting a circular nonparametric Von Mises kernel probability density function to the radian-transformed detection records, regarded as a random sample from the underlying continuous temporal distribution describing the species' true activity pattern $[29,31]$. We obtained standard errors by nonparametric bootstrap resampling with 500 iterations [31,32] and used the Wald statistic to assess the difference between probability density functions describing the two species' activity levels, tested on chi-square distribution with 1 degree of freedom [32].

We estimated the temporal segregation in waterhole use by African wolves and side-striped jackals through the coefficient of activity overlap $(\Delta)$, applied to kernel probability density functions. This coefficient ranges from 0 (no overlap) to 1 (complete overlap), and describes the degree of similarity between the two kernel density curves [29,31]. Therefore, it indicates the relative likelihood that the two species are simultaneously at waterholes [31]. Following [33], we considered waterhole use overlap as "low" if $\Delta<0.66$; "moderate" if $0.66 \leq \Delta<0.76$; and "high" if $\Delta \geq 0.76$. We used the Mardia-Watson-Wheeler test (MWW test; [34]) to assess the significance of the differences in the diel waterhole using patterns between our target species [7]. We performed all activity estimation calculations using the package "activity" [35], whereas the MWW test was performed with the "circular" package [36], both in R software [37].

We estimated spatiotemporal segregation using a time-to-encounter approach, following [38]. Firstly, we created a matrix of species encounters organized by camera-trapping station, date and time. For every detection record, we calculated the minimum time to the subsequent detection between both species. We generated the expected statistical distributions of time-to-encounter by randomly assigning encounter times in 1000 simulations. Thus, by comparing the median observed time-to-encounter with the simulated expected statistical distributions, we determined whether there is segregation (i.e., larger observed time-to-encounter than expected) or association (i.e., smaller observed time-to-encounter than expected) between both our target species.

\section{Results}

\subsection{Detection Rates of Carnivore Species}

We obtained a total of 1438 camera-trapping videos comprising animal events in which 708 were independent detection records. Independent records included several groups: livestock $(\mathrm{n}=251 ; 35 \%)$, carnivores $(n=232 ; 33 \%)$, birds $(n=212 ; 30 \%)$ and small mammals $(n=12 ; 2 \%)$ (Table S1). Eight carnivore species from five Families (Canidae, Felidae, Mustelidae, Viverridae and Hyaenidae) were detected, of which African wolves (21.6 records per 100 night-traps) and side-striped jackals (31.6 records per 
100 night-traps) were by far the most frequently detected, comprising $31 \%(n=71)$ and $45 \%(n=104)$ of all carnivore records, respectively.

\subsection{Canid Group Size Near Waterholes}

Adults were the most commonly detected age class for both canid species. Pups were only recorded for African wolves, comprising 18\% $(n=13)$ of this species' detections.

Group size varied from 1 to 4 individuals for African wolves, and from 1 to 2 individuals for side-striped jackals, with single individuals comprising most records for both species, i.e., $73 \%(n=52)$ and $79 \%(n=82)$, respectively. The maximum group size was composed by two adults and two pups for African wolves, and by two adults for side-striped jackals.

Single African wolf individuals were most commonly detected from November through to January, with groups of more than two individuals being most commonly detected in February and March, due to the recruitment of pups (Figure 2). For side-striped jackals, both single individuals and pairs were more frequently detected in December.

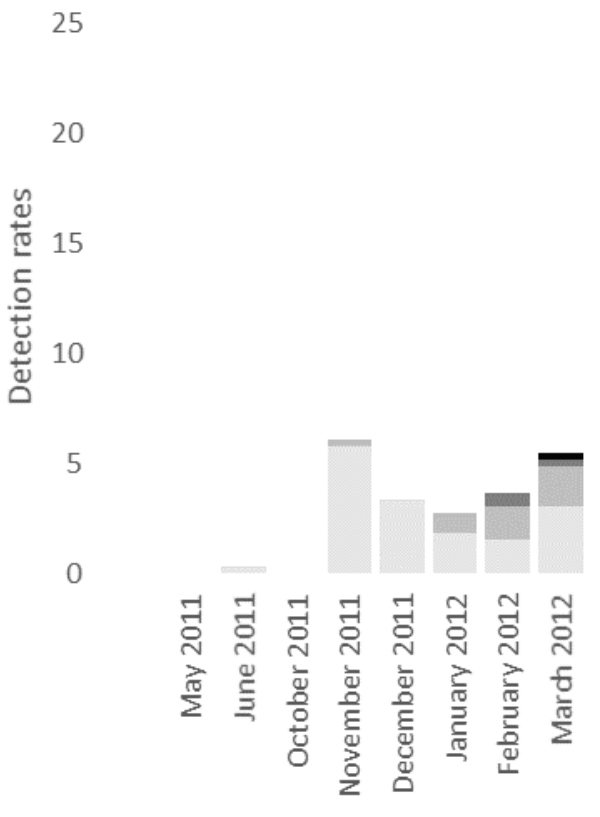

Canis lupaster

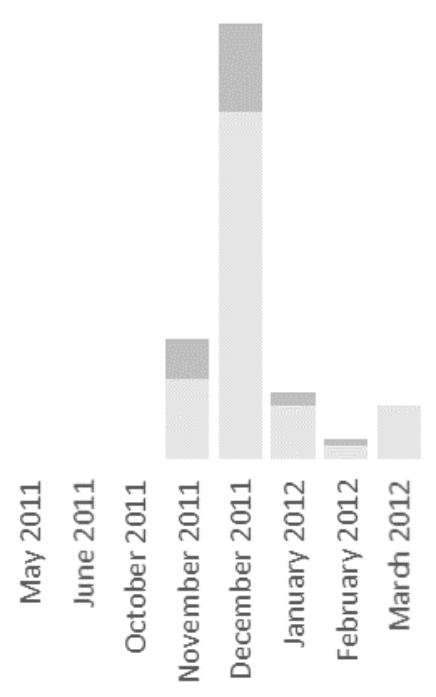

Canis adustus

\section{Number of individuals}

$1=2 \square 3 \square 4$

Figure 2. Temporal variation in the number of detected individuals for African wolves and side-striped jackals, based on detection rates (number of independent records/total trapping effort) per 100 night-traps by camera trapping near artificial waterholes in the Ferlo region (Senegal).

\subsection{Canid Activity Patterns Near Waterholes}

African wolves and side-striped jackals tended to spend an equivalent amount of time active at waterholes, although the latter appeared to reveal a tendency to use this resource for slightly longer during the day (Table 1$)$. However, both species showed a high activity overlap $(\Delta=0.85)$, with a bimodal activity pattern in waterhole use. African wolves and side-striped jackals exhibited a clear crepuscular pattern in waterhole use, with less intense activity during mid-night time. There were slight differences in the patterns of waterhole use by these two canids as African wolves appeared to reach their activity peak earlier at sunset and later at sunrise than side-striped jackals; however, these differences were not significant (Figure 3). 
Table 1. Activity level (proportion of time spent at waterholes) and estimated coefficient of activity overlap $(\Delta)$ between African wolves and side-striped jackals based on detection records by camera trapping near artificial waterholes in the Ferlo region (Senegal). CI: Confidence interval, W: Mardia-Watson-Wheeler test statistic.

\begin{tabular}{ccccc}
\hline Species & Activity Level (h) & $\mathbf{9 5 \%}$ CI & W & $p$-Value \\
\hline Canis lupaster & $11.7 \pm 1.6$ & $7.5-13.5$ & & \\
Canis adustus & $12.3 \pm 1.5$ & $8.4-14.1$ & & \\
Difference & $-0.7 \pm 2.2$ & & 0.09 & 0.77 \\
Activity overlap $(\Delta)$ & 0.85 & & 67.05 & $2.75 \times 10^{-15}$ \\
\hline
\end{tabular}

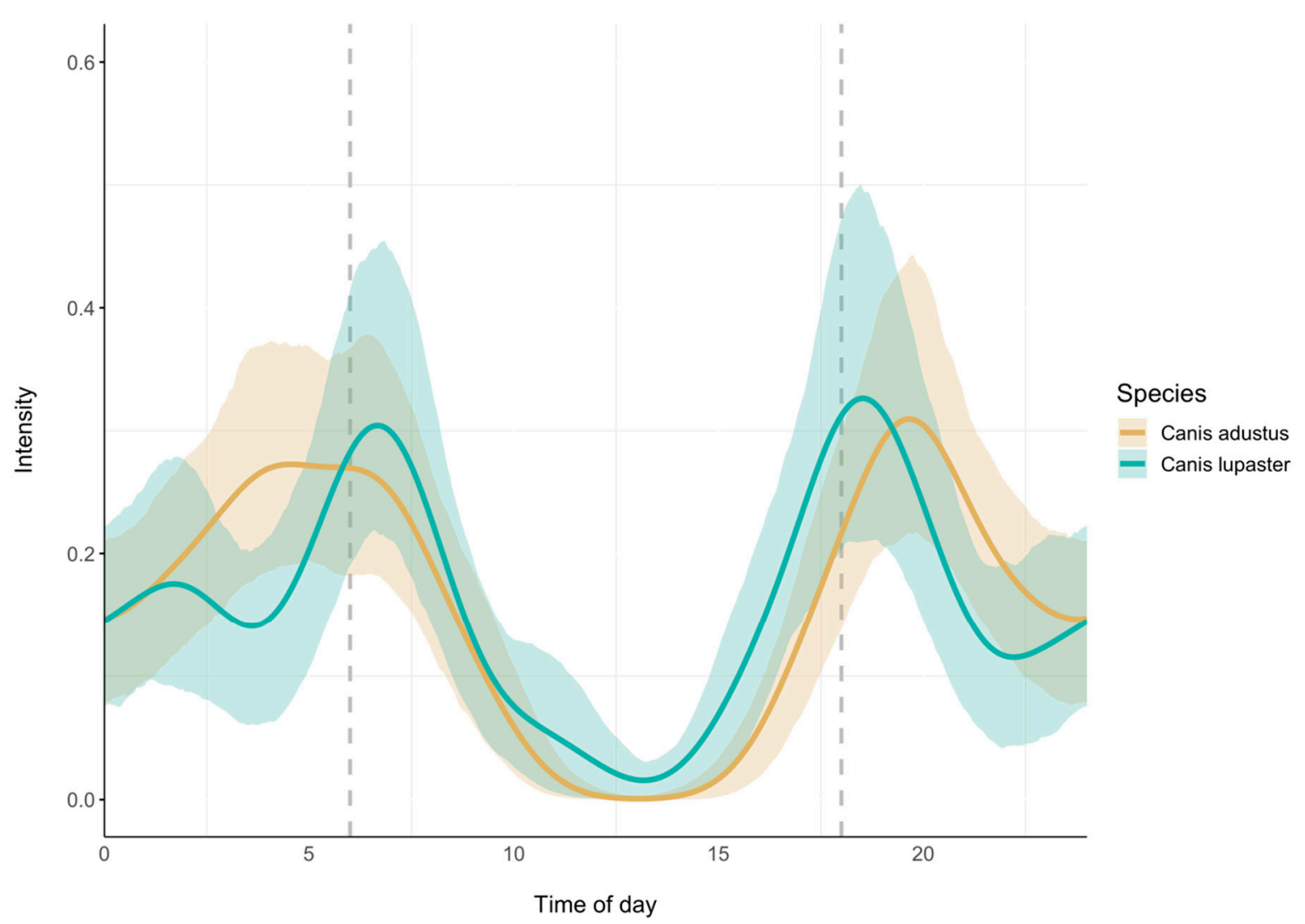

Figure 3. Circadian activity patterns of African wolves (green line) and side-striped jackals (yellow line) based on detection records by camera trapping near artificial waterholes in the Ferlo region (Senegal). Dashed lines represent sunrise (06h00) and sunset (18h00). Shaded areas represent $95 \%$ confidence intervals based on bootstrap resampling.

Time to species detection differed (Figure 4). The observed amount of time for side-striped-jackal detection was $21.6 \mathrm{~h}$ after African wolves, and the opposite occurring after $13.4 \mathrm{~h}$. The probability of obtaining a longer time period to detect side-striped-jackal after an African wolf detection was $71 \%$, whereas the opposite was only of $12 \%$. These results indicate that side-striped jackals took a longer time than expected to be detected at waterholes upon a previous detection of African wolves while the opposite did not occur. 


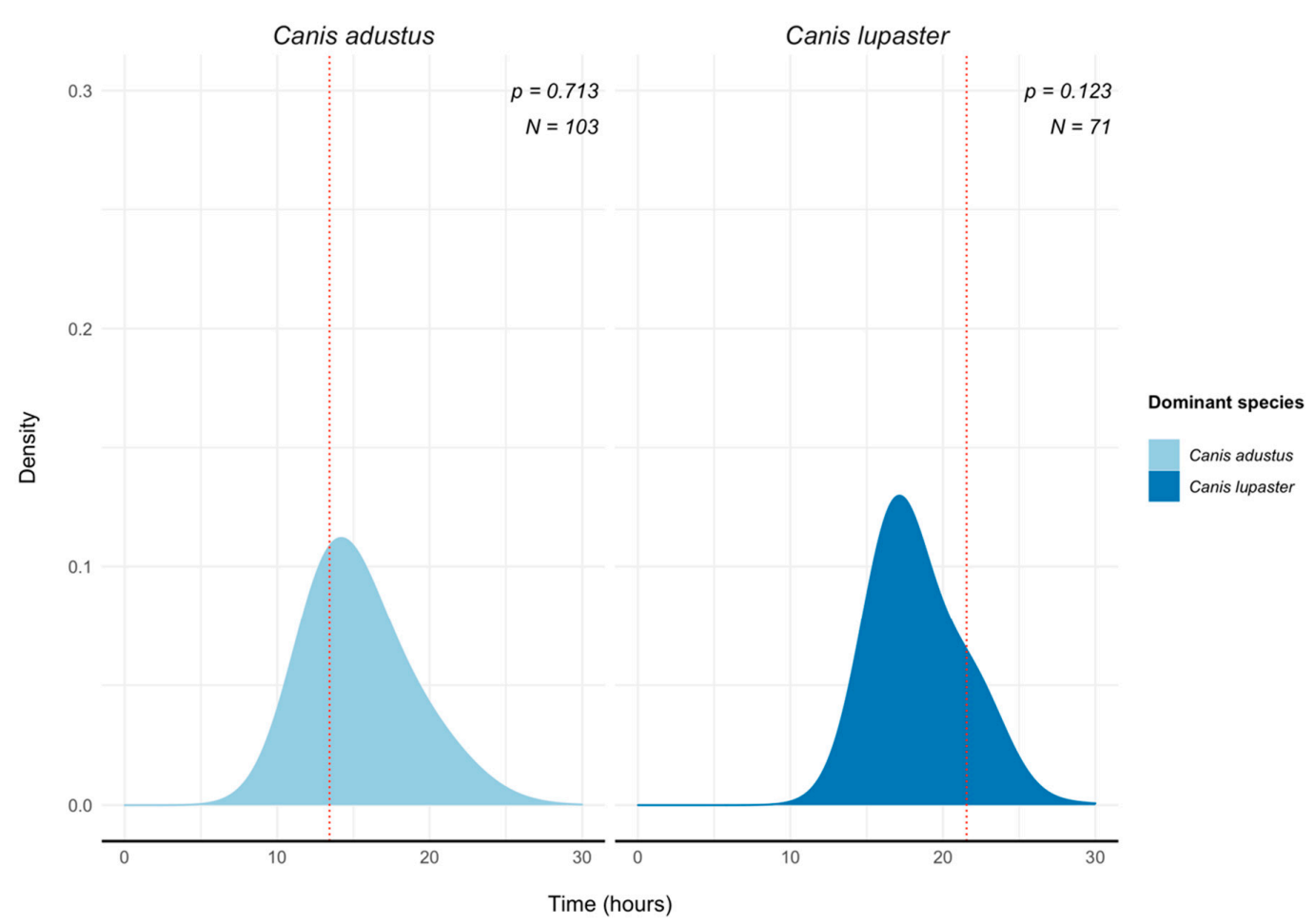

Figure 4. Time-to-encounter analysis between African wolves (dark blue) and side-striped jackals (light blue) at artificial waterholes in the Ferlo region (Senegal). Vertical lines represent median minimum time-to-encounter of the other species. Shaded areas represent simulated expected distributions.

\section{Discussion}

Our results provide valuable insights into the group size and activity patterns of two poorly known canid species, when occurring in sympatry and using a limited resource. We found that both African wolves and side-striped jackals use waterholes most frequently alone, although the former species also occurred in small family groups. Our findings are consistent with previous reports $[13,17,19,21]$ describing both canids as mostly solitarily foragers despite occurring in pairs or family groups, with the basis of the group unit being the mated pair, which can be stable over several years [19]. In our study area, temporal variations in group size for African wolves are consistent with what would be expected from the reproductive behaviour of this canid. All detected pups were estimated to be $2-3$ months old, resulting in an estimated birth season during November-December. This seasonality is consistent with previous reports from Tanzania, where mating typically occurs from October to December, and births in December through to March [39]. African wolves are reported to give birth to their young in dens where parents and helpers feed and guard their offspring during pup dependency $[39,40]$. Furthermore, males also provide for their mates during pregnancy and both the breeding male and helpers provide for females during lactation $[39,40]$. Therefore, we hypothesize that during the early breeding season (November/December) single individuals were detected more frequently in our study area because females could be in den sites nursing new-born pups. Towards January and February, the frequency of detection of groups of two adult individuals increases, as the breeding pair would begin to forage together to provide food for pups in the den and as they grow, pups started being included in foraging movements leading to the larger groups detected in March.

Alloparental behaviour, in which yearlings remain with their parents to help raise younger siblings, has been suggested to occur in many canid species, including African wolves and side-striped jackals [19,41-43]. However, our data from the Ferlo region do not support this evidence as only two adults, presumably the breeding pair, were detected alongside the pups. This result could be related to the limited availability of food resources in the semi-arid environment of our study area, 
as larger group sizes including the presence of helpers are frequently related to regions with high productivity and abundant prey $[19,39,40,44]$.

For side-striped jackals, litters of four to six pups have been reported to be born from August to November in Southern Africa [19,43,45]. Despite pup mortality being considered high in this canid [19], we speculate that the lack of side-striped jackal pups' detection is likely related to a late breeding season occurring in the Ferlo region due to differences in the reproductive period between the northern and southern hemispheres, rather than a true absence of reproduction. A late breeding season may explain the absence of pup detections during our sampling period (i.e., until March), as by this time pups would still be dependent, not moving with the adults far from the den site. Therefore, our findings may suggest a possible shift of reproductive behaviour between the two species in our study area. However, the absence of data regarding the reproductive behaviour of side-striped jackals, particularly in West Africa, prevents us from drawing sustained conclusions.

Our results suggest for both canids a clear avoidance of mid-day and early afternoon activity at waterholes, presumably because of the high temperatures reached during daytime as reported in other mammalian carnivores occurring in semi-arid environments (e.g., [46-48]). The nocturnal and crepuscular waterhole use by both African wolves and side-striped jackals is congruent with previous studies addressing patterns of circadian activity in both canid species. African wolves are known to be mainly crepuscular, but show flexible activity patterns as they may be active during the day in areas of low human disturbance or high food availability [19-21]. Side-striped jackals are considered to be primarily nocturnal [19], although they can adapt their activity patterns if persecuted or to reduce interspecific competition [19], as shown in areas of East Africa where they occur in sympatry with black-backed jackals (Canis mesomelas) [24]. Accordingly, in our study area we also found some evidences of spatiotemporal segregation between side-striped jackals and African wolves co-occurring at artificial waterholes.

Overall, we found a high activity overlap between African wolves and side-striped jackals during the use of a shared limited resource, apparently contradicting our initial hypothesis in which we expected our study species to segregate around waterholes to reduce competition. However, our time-to-encounter results suggest differently, indicating the occurrence of some spatiotemporal avoidance with side-striped jackals taking longer than expected to be detected after the occurrence of African wolves while the opposite did not occur, suggesting African wolves to be the dominant species. Previous studies $[47,48]$ on waterhole use by carnivores in semi-arid environments have reported little or no evidence of interference competition, presumably due to their reduced water demand, especially when compared to desert herbivores [47]. More widely, another study of African carnivores [6], which included the African wolf and side-striped jackal, suggested that interspecific competition is highly important for a large number of species. In particular, both canids were amongst the most vulnerable species in regard to the potential of having their resources stolen by competitors [6]. Thus, temporal or spatial segregation can be a good strategy to minimize agonistic encounters, as already reported in several studies regarding carnivore niche overlap and resource partitioning [3,14,20,49]. Accordingly, our results suggest a unidirectional spatiotemporal segregation relationship, with side-striped jackals tending to avoid agonistic interactions with African wolves, supportive of some degree of resource partitioning as a result of interference competition between our study species.

As climate change progresses, arid ecosystems are expected to have increasing temperatures and aridity, which will likely contribute to turn water into an even more limiting resource [50]. In fact, forecasted changes in rainfall variability and in annual rainfall, which is predicted to decrease, are reported to have a strong impact in the Ferlo region [26]. As water availability decreases and aridity increases, a higher dependence of wildlife on the few remaining waterholes is expected [5]. Although wildlife species occurring in the Sahel ecoclimatic zone have always struggled with low water availability $[8,26]$, the increasing loss of this major selective resource in these semi-arid environments might pose additional challenges for all wildlife and further increase competitive stress near the 
available water resources. These effects, coupled with human population growth and increased conflicts between wildlife and human activities (such as livestock production), will lead to an urgent need for a deeper knowledge on wildlife interactions near water sources as well as the implementation of specific conservation measures, such as the construction of artificial waterholes for exclusive wildlife use.

\section{Conclusions}

Based on our findings, we describe African wolves and side-striped jackals as mostly solitary with nocturnal and crepuscular diel activity when using waterholes in a semi-arid environment. However, we found some spatiotemporal segregation, suggesting the occurrence of unidirectional interspecific competition for a shared limited resource, with African wolves being the dominant species. To our knowledge, our study provides the only available camera-trapping data on African wolves and side-striped jackals in the Sahel ecoclimatic zone of West Africa. This approach allowed us to address knowledge gaps in group size, breeding phenology and activity patterns of these two species when in sympatry, providing relevant and innovative data that enhances the biological knowledge and supports conservation actions for these poorly known canids. Our findings and methodological approach also provide useful insights for future wildlife studies investigating niche partitioning on the use of limited resources. Furthermore, as an important conservation action, our study highlights the need of constructing artificial waterholes in regions with a prolonged dry season. Additionally, our camera trapping approach allowed reporting the presence of several regionally endangered carnivores in West Africa [19] at waterholes, such as Serval (Leptailurus serval), Caracal (Caracal caracal) and Stripped Hyena (Hyaena hyaena), which highlights the relevance of the Ferlo region for wildlife conservation in Senegal and, more generally, within the Sahel ecoclimatic zone.

Supplementary Materials: The following are available online at http:/www.mdpi.com/1424-2818/12/12/477/s1, Figure S1: Temporal variation in sampling effort by camera-trapping (A) and sampling effort for each of the 5 cameras placed near artificial waterholes in Ferlo (B), Table S1: Total number of independent records and detection rates (number of independent records/total trapping effort) per 100 night-traps for each recorded species considering carnivores, small mammals, birds and livestock, obtained by camera trapping near artificial waterholes in the Ferlo region (Senegal).

Author Contributions: Conceptualization: M.J.P., P.M. and F.Á.; Field work and Data Collection: J.F.L.; Methodological procedures and formal analysis: M.J.P. and P.M.; Writing-original draft preparation: M.J.P. and F.Á.; Writing—review and editing: M.J.P., J.F.L., P.M. and F.Á.; Supervision: F.Á.; Funding acquisition: J.F.L. All authors have read and agreed to the published version of the manuscript.

Funding: Organismo Autónomo de Parques Nacionales, Ministério de Medio Ambiente de España (MMAE).

Acknowledgments: To “Direction des Parcs Nationaux de la République du Sénégal, Ministère de l’Environnement et du Développement Durable de la République du Sénégal", namely Colonel Mamme Balla Gueye (Director of PN Senegal) and Lieutenant Thialao Sarr (Curator of Ferlo Nord Wildlife Reserve), for all the logistic support and for issuing the permits to conduct field expeditions in Senegal. We also acknowledge "Organismo Autónomo de Parques Nacionales, Ministério de Medio Ambiente de España" (MMAE), namely Francisco José Cantos Mengs (responsible for the cooperation program with Senegal) for allowing to use all data collected in previous field expeditions. To Joaquin Sanz for helping during field work in Senegal. PM was supported by UID/BIA/50027/2019 with funding from FCT/MCTES through national funds.

Conflicts of Interest: The authors declare no conflict of interest.

\section{References}

1. Halle, S. Ecological relevance of daily activity patterns. In Activity Patterns in Small Mammals: An Ecological Approach; Halle, S., Stenseth, N.C., Eds.; Springer: New York, NY, USA, 2000; Volume 141, pp. 67-90.

2. Kronfeld-Schor, N.; Dayan, T. Partitioning of Time as an Ecological Resource. Annu. Rev. Ecol. Evol. Syst. 2003, 34, 153-181. [CrossRef]

3. Linnell, J.D.C.; Strand, O. Interference interactions, co-existence and conservation of mammalian carnivores. Divers. Distrib. 2000, 6, 169-176. [CrossRef]

4. Vahl, W.K.; Van Der Meer, J.; Weissing, F.J.; Van Dullemen, D.; Piersma, T. The mechanisms of interference competition: Two experiments on foraging waders. Behav. Ecol. 2005, 16, 845-855. [CrossRef] 
5. Valeix, M.; Chamaillé-Jammes, S.; Fritz, H. Interference competition and temporal niche shifts: Elephants and herbivore communities at waterholes. Oecologia 2007, 153, 739-748. [CrossRef] [PubMed]

6. Caro, T.M.; Stoner, C.J. The potential for interspecific competition among African carnivores. Biol. Conserv. 2003, 110, 67-75. [CrossRef]

7. Gerber, B.D.; Karpanty, S.M.; Randrianantenaina, J. Activity patterns of carnivores in the rain forests of Madagascar: Implications for species coexistence. J. Mammal. 2012, 93, 667-676. [CrossRef]

8. Brito, J.C.; Godinho, R.; Martínez-Freiría, F.; Pleguezuelos, J.M.; Rebelo, H.; Santos, X.; Vale, C.G.; Velo-Antón, G.; Boratyński, Z.; Carvalho, S.B.; et al. Unravelling biodiversity, evolution and threats to conservation in the sahara-sahel. Biol. Rev. 2014, 89, 215-231. [CrossRef]

9. Wilson, J.S.; Pitts, J.P. Identifying Pleistocene refugia in North American cold deserts using phylogeographic analyses and ecological niche modelling. Divers. Distrib. 2012, 18, 1139-1152. [CrossRef]

10. Schulz, E.; Abichou, A.; Adamou, A.; Ousseïni, I.; Ballouche, A. The desert in the Sahara. Transitions and boundaries. In Palaeoecology of Africa and the Surrounding Islands; Baumhauer, R., Runge, J., Eds.; Taylor \& Francis Group: London, UK, 2009; Volume 29, pp. 63-89.

11. Thrash, I.; Theron, G.K.; Bothma, J.P. Dry season herbivore densities around drinking troughs in the Kruger National Park. J. Arid Environ. 1995, 29, 213-219. [CrossRef]

12. Wilson, W.G.; Richards, S.A. Consuming and grouping: Recource-mediated animal aggregation. Ecol. Lett. 2000, 3, 175-180. [CrossRef]

13. Macdonald, D.W.; Sillero-Zubiri, C. Biology and Conservation of Wild Canids; Oxford University Press: Oxford, UK, 2004.

14. Vieira, E.M.; Port, D. Niche overlap and resource partitioning between two sympatric fox species in southern Brazil. J. Zool. 2007, 272, 57-63. [CrossRef]

15. Hoffmann, M.; Atickem, A. Canis lupaster. The IUCN Red List Threatened Species 2019: e.T118264888A118265889. Available online: https://dx.doi.org/10.2305/IUCN.UK.2019-1.RLTS. T118264888A118265889.en (accessed on 14 December 2020).

16. Koepfli, K.P.; Pollinger, J.; Godinho, R.; Robinson, J.; Lea, A.; Hendricks, S.; Schweizer, R.M.; Thalmann, O.; Silva, P.; Fan, Z.; et al. Genome-wide evidence reveals that African and Eurasian golden jackals are distinct species. Curr. Biol. 2015, 25, 2158-2165. [CrossRef] [PubMed]

17. Castelló, J.R. Canids of the World: Wolves, Wild Dogs, Foxes, Jackals, Coyotes and their Relatives; Princeton University Press: Princetion, UK, 2018.

18. Eddine, A.; Mostefai, N.; De Smet, K.; Klees, D.; Ansorge, H.; Karssene, Y.; Nowak, C.; Van Der Leer, P. Diet composition of a newly recognized canid species, the African Golden Wolf (Canis anthus), in Northern Algeria. Ann. Zool. Fennici. 2017, 54, 347-356. [CrossRef]

19. Wilson, D.; Mittermeier, R.A. Handbook of the Mammals of the World. Vol. 1. Carnivores; Lynx Edicions: Barcelona, Spain, 2009.

20. Karssene, Y.; Chammem, M.; Li, F.; Eddine, A.; Hermann, A.; Nouira, S. Spatial and temporal variability in the distribution, daily activity and diet of fennec fox (Vulpes zerda), red fox (Vulpes vulpes) and African golden wolf (Canis anthus) in southern Tunisia. Mamm. Biol. 2019, 95, 41-50. [CrossRef]

21. Admasu, E.; Thirgood, S.J.; Bekele, A.; Laurenson, M.K. Spatial ecology of golden jackal in farmland in the Ethiopian Highlands. Afr. J. Ecol. 2004, 42, 144-152. [CrossRef]

22. Gaubert, P.; Bloch, C.; Benyacoub, S.; Abdelhamid, A.; Pagani, P.; Djagoun, C.A.M.S.; Couloux, A.; Dufour, S. Reviving the African Wolf Canis lupus lupaster in North and West Africa: A Mitochondrial Lineage Ranging More than $6000 \mathrm{~km}$ Wide. PLoS ONE 2012, 7, e42740. [CrossRef]

23. Rueness, E.K.; Asmyhr, M.G.; Sillero-Zubiri, C.; Macdonald, D.W.; Bekele, A.; Atickem, A.; Stenseth, N.C. The cryptic African wolf: Canis aureus lupaster is not a golden jackal and is not endemic to Egypt. PLoS ONE 2011, 6, e16385. [CrossRef]

24. Fuller, T.K.; Biknevicius, A.R.; Kat, P.W.; Van Valkenburgh, B.; Wayne, R.K. The ecology of three sympatric jackal species in the Rift Valley of Kenya. Afr. J. Ecol. 1989, 27, 313-323. [CrossRef] 
25. Hall, L.K.; Larsen, R.T.; Knight, R.N.; McMillan, B.R. Feral horses influence both spatial and temporal patterns of water use by native ungulates in a semi-arid environment. Ecosphere 2018, 9, e02096. [CrossRef]

26. Hein, L.; Metzger, M.J.; Leemans, R. The local impacts of climate change in the Ferlo, Western Sahel. Clim. Chang. 2009, 93, 465-483. [CrossRef]

27. Becker, B. The contribution of wild plants to human nutrition in the Ferlo (Northern Senegal). Agrofor. Syst. 1983, 1, 257-267. [CrossRef]

28. Ndiaye, I. Caracterisation Du Noyau Central De La Reserve De Faune Du Ferlo Nord.; Thecnical Report; Projet de Gestion Integree des Ecosystemes: Dakar, Senegal, 2006.

29. Linkie, M.; Ridout, M.S. Assessing tiger-prey interactions in Sumatran rainforests. J. Zool. 2011, 284, $224-229$. [CrossRef]

30. Monterroso, P.; Alves, P.C.; Ferreras, P. Catch Me If You Can: Diel Activity Patterns of Mammalian Prey and Predators. Ethology 2013, 119, 1044-1056. [CrossRef]

31. Ridout, M.S.; Linkie, M. Estimating overlap of daily activity patterns from camera trap data. J. Agric. Biol. Environ. Stat. 2009, 14, 322-337. [CrossRef]

32. Rowcliffe, J.M.; Kays, R.; Kranstauber, B.; Carbone, C.; Jansen, P.A. Quantifying levels of animal activity using camera trap data. Methods Ecol. Evol. 2014, 5, 1170-1179. [CrossRef]

33. Monterroso, P.; Alves, P.C.; Ferreras, P. Plasticity in circadian activity patterns of mesocarnivores in Southwestern Europe: Implications for species coexistence. Behav. Ecol. Sociobiol. 2014, 68, 1403-1417. [CrossRef]

34. Batschelet, E. Circular Statistics in Ecology; Academic Press: London, UK, 1981.

35. Rowcliffe, M. Activity: Animal Activity Statistics, Version 1.3. Available online: https://cran.r-project.org/ web/packages/activity/index.html (accessed on 14 December 2020).

36. Agostinelli, C.; Lund, U. R package "circular": Circular Statistics, Version 0.4-93. Available online: https://cran.r-project.org/web/packages/circular/index.html (accessed on 14 December 2020).

37. R Core Team. R: A Language and Environment for Statistical Computing; R Foundation for Statistical Computing: Vienna, Austria, 2017.

38. Karanth, K.U.; Srivathsa, A.; Vasudev, D.; Puri, M.; Parameshwaran, R.; Kumar, N.S. Spatio-temporal interactions facilitate large carnivore sympatry across a resource gradient. Proc. R. Soc. B Biol. Sci. 2017, 284, 20161860. [CrossRef]

39. Moehlman, P.D. Intraspecific Variation in Canid Social Systems. In Carnivore Behavior, Ecology, and Evolution; Cornell University Press: Ithaca, NY, USA, 1989; pp. 143-163.

40. Moehlman, P.D.; Hofer, H. Cooperative Breeding, Reproductive Suppression, and Body Mass in Canids. In Cooperative Breeding in Mammals; Cambridge University Press: Cambridge, UK, 1997; pp. 76-128.

41. Moehlman, P.D. Jackal helpers and pup survival. Nature 1979, 277, 382-383. [CrossRef]

42. Ferguson, J.W.H.; Nel, J.A.J.; Wet, M.J. Social organization and movement patterns of Black- backed jackals Canis mesomelas in South Africa. J. Zool. 1983, 199, 487-502. [CrossRef]

43. Loveridge, A.J.; Macdonald, D.W. Seasonality in spatial organization and dispersal of sympatric jackals (Canis mesomelas and C. adustus): Implications for rabies management. J. Zool. 2001, 253, 101-111. [CrossRef]

44. Estes, R.D. The Behavior Guide to African Mammals: Including Hoofed Mammals, Carnivores, Primates; University of California Press: Berkeley, CA, USA, 1992.

45. Bingham, J.; Purchase, G.K. Reproduction in the jackals Canis adustus Sundevall, 1846, and Canis mesomelas Schreber, 1778 (Carnivora: Canidae), in Zimbabwe. Afr. Zool. 2002, 37, 21-26. [CrossRef]

46. Edwards, S.; Al Awaji, M.; Eid, E.; Attum, O. Mammalian activity at artificial water sources in Dana Biosphere Reserve, southern Jordan. J. Arid Environ. 2017, 141, 5255. [CrossRef]

47. Ochoa, G.V.; Chou, P.P.; Hall, L.K.; Knight, R.N.; Larsen, R.T.; McMillan, B.R. Spatial and temporal interactions between top carnivores at water sources in two deserts of western North America. J. Arid Environ. 2021, 184, 104303. [CrossRef]

48. Sutherland, K.; Ndlovu, M.; Pérez-Rodríguez, A. Use of Artificial Waterholes by Animals in the Southern Region of the Kruger National Park, South Africa. Afr. J. Wildl. Res. 2018, 48, 023003. [CrossRef] 
49. Lucherini, M.; Reppucci, J.I.; Walker, R.S.; Villalba, M.L.; Wurstten, A.; Gallardo, G.; Iriarte, A.; Villalobos, R.; Perovic, P. Activity Pattern Segregation of Carnivores in the High Andes. J. Mammal. 2009, 90, 1404-1409. [CrossRef]

50. Cook, B.I.; Smerdon, J.E.; Seager, R.; Coats, S. Global warming and 21st century drying. Clim. Dyn. 2014, 43, 2607-2627. [CrossRef]

Publisher's Note: MDPI stays neutral with regard to jurisdictional claims in published maps and institutional affiliations.

(C) 2020 by the authors. Licensee MDPI, Basel, Switzerland. This article is an open access article distributed under the terms and conditions of the Creative Commons Attribution (CC BY) license (http://creativecommons.org/licenses/by/4.0/). 